\title{
A Descriptive Correlational Survey to Assess the Knowledge Related to Prevention of Nosocomial Infections and Selected Practices among Staff Nurses in a Selected Hospital of New Delhi
}

\author{
Geetanjali $^{1}$, Cimil Babu ${ }^{2}$ \\ ${ }^{1} P G$ Tutor, Faculty of Nursing, SGT University, Budhera-Gurugram, Haryana, ${ }^{2}$ Professor, \\ Department of Obstetrics \& Gynecological Nursing, Holy Family College of Nursing, New Delhi
}

\begin{abstract}
A Descriptive Correlational Survey to assess the knowledge related to prevention of Nosocomial Infections and selected practices among staff nurses in selected nursing care units of a selected Hospital of New Delhi. The objectives of the study were to assess knowledge and selected practices of staff nurses regarding prevention of nosocomial infections, to seek relationship between knowledge and hand washing practice, to seek relationship between knowledge and IV injection practice and to seek association between knowledge, hand washing practice and IV injection practice with their demographic variables. 60 staff nurses were selected by using convenient sampling. A knowledge questionnaire and two observational checklists were developed to determine the knowledge and selected practices related to hand washing and IV injection procedure. Knowledge questionnaire consisted of 30 items and two observational checklists for hand washing procedure consisted of 12 items and IV injection procedure consisted of 21 items. After obtaining permission from Administrative and Ethical committee, the data collection was done in the month of Dec.Jan. The findings of the study revealed that mean percentage of knowledge seen $(62.73 \%)$, mean percentage of hand washing practice seen $(61.42 \%)$ and mean percentage of IV injection practice seen $(53.19 \%)$. Karl Pearson correlation was used to check the relationship between knowledge and selected practices showed there was no significance between knowledge and practice scores. Statistical significance were only found between knowledge scores with variable like no. of times attended in service education but there was no significance found with other variables. Also, there was statistical significance found between hand washing practice and IV injection practice with variable like current area of posting but there was no association found with other variables. Based on the findings, recommendations proposed for future research.
\end{abstract}

Keywords: Knowledge, selected practices and staff nurses.

\section{Introduction}

The word "health" refers to a state of complete emotional and physical well-being. It refers not only to the absence of disease but the ability to recover from illness. Health services can be described as permanent

\section{Corresponding Author:}

Ms. Cimil Babu

Professor, Department of Obstetrics \& Gynecological Nursing, Holy Family College of Nursing, New Delhi e-mail: cimilbabu@gmail.com country wide system of established institutions, objective of which is to cope with the various health needs and demands of the population, and thereby provide health care to individuals and the community, including a broad spectrum of preventive, promotive, curative and rehabilitative activities, and utilizing, to a large extent. Patients in health care settings, especially Hospitals and long term care facilities, are at a higher risk for infection than those patients seen at home ${ }^{1}$.

Health care-associated infection (HAI), also referred to as "Nosocomial" or "Hospital" infection, is an infection occurring in a patient while receiving care 
in a Hospital or other health care facility which was not present or incubating at the time of admission ${ }^{2}$. It results due to the exposure of microorganism in the Hospital settings. These infections typically occur within 72 hours of hospitalization by the micro-organisms by the patients or originates from the animate or inanimate environment of the Hospital itself ${ }^{3}$.

Several factors that may cause HCAI are prolonged and inappropriate use of invasive devices and antibiotics, High-risk and sophisticated procedures, insufficient application of standard and isolation precautions, inadequate environmental hygienic conditions of Hospitals, inappropriate bio-medical waste management about HCAI, overcrowding, poor knowledge and lack of application of basic infection control measures, lack of knowledge regarding injection and blood transfusion procedures, absence of local and National guidelines and policies regarding HCAI and malpracticing aseptic procedures ${ }^{4}$.

Health care workers play an important role in preventing health care associated infections, as patient advocates, Health care worker has many tools to create a safe environment for patients. Standard universal precaution is one of the aspect of safe environment which is being provided for patients ${ }^{5}$.

Hospitals in India have a high burden of infections in their intensive care units (ICU) and general wards, many of which are resistant to antibiotic treatment ${ }^{6}$.

According to WHO (2016), Patient Safety is actively working towards establishing effective ways of improving global health care and save lives lost to health care associated infections.

"Clean Care is Safer Care" programme initiated by WHO aiming reducing health care-associated infections globally and has placed improving hand hygiene practices at the core of achieving this ${ }^{4}$.

Nurses in all roles and settings can demonstrate leadership in infection prevention and control by using their knowledge, skill and judgement to initiate appropriate and immediate infection control procedures. There is a need to practice diligently so that patients will be safe ${ }^{7}$.

According to some studies, there is lack of hand hygiene practices in the Hospitals and also there is presence of knowledge regarding hand hygiene or universal precautions but there is reluctance to adhere with it or sometimes they don't feel the need to maintain standard precautions of many reasons as they should engage in interventions on proper sanitation and hygiene procedures such as hand washing, disposing of medical waste products like used syringes, and cleaning up of patients environment to prevent deadly bacteria from harboring the patient's environment and cause infection ${ }^{8}$.

Problem Statement: A descriptive correlational survey to assess the knowledge related to prevention of Nosocomial Infections and selected practices among staff nurses in selected nursing care units of a selected Hospital of New Delhi.

\section{Objectives:}

- To assess knowledge of staff nurses working in selected nursing care units regarding prevention of nosocomial infections.

- To assess selected practices of staff nurses working in selected nursing care units regarding prevention of nosocomial infections.

- To seek relationship between knowledge and hand washing practice of staff nurses working in selected nursing care units regarding prevention of nosocomial infections.

- To seek relationship between knowledge and IV injection practice of staff nurses working in selected nursing care units regarding prevention of Nosocomial Infections.

- To seek association between knowledge with the demographic variables of staff nurses.

- To seek association between hand washing practice with the demographic variables of staff nurses.

- To seek association between IV injection practice with the demographic variables of staff nurses.

\section{Operational Definition:}

- Knowledge: It is the information regarding Nosocomial Infection and its preventable measures.

- Selected Practices: Actions of staff nurses while performing procedures i.e. hand washing procedure and IV injection procedure.

- Nursing Care Units: In this study, it refers to Medical, Surgical and Obstetrical and Gynaecological patient's care units. 
Conceptual Framework: Conceptual framework of the present study is based on General System Theory by Ludwig Von Bertalanffy.

The conceptual framework consists of three phases: input, process and output.

Input: Refers to the target group i.e. staff nurses working in nursing care units of selected Hospital, Delhi and their existing demographic variables like age in years, educational qualification, professional experience, current area of posting, attended in service education or not, no. of times in service education attended.

Process: In this present study, process refers to the selection of the study subjects, development of tool, validation of tool, try out, pilot study, assessment of knowledge by using knowledge questionnaire, assessment of practice by using observational checklist, assessment of relationship between knowledge and practice and assessment of association between knowledge and practice with their socio demographic data.

Output: Refers to the evaluation of study in terms of level of knowledge and practice regarding prevention of Nosocomial Infection.

Feedback: In this study, feedback is the assessment of knowledge and practice of staff nurses which is not included in the study.

\section{Methodology}

Research Approach: The research approach utilized in the present study was Quantitative approach.

Research Design: The research design adopted for the present study was Descriptive Correlational Survey design.

Setting of the Study: The setting for the study was Holy Family Hospital in New Delhi.

Population: The population was the staff nurses working in selected Hospital of New Delhi.

Sample: Sample in this study were the staff nurses working in Medical, Surgical and Obstetrical and Gynecological units in selected Hospital.

Sampling Technique: Sampling technique used was non probability convenient sampling.
Sample Size: Size of the sample were 60 staff nurses.

\section{Inclusion Criteria:}

- Staff nurses working in Medical, Surgical and Obstetrical and Gynaecological units.

- Available during the time of data collection.

- Willing to participate in the study.

\section{Exclusion Criteria:}

- Staff nurses working in other units.

\section{Findings:}

1. The findings regarding sample characteristics related that

- Majority 53 out of $60(88.3 \%)$ of subjects were in the age group of $21-30 y e a r s$ and $6(10 \%)$ were in the age group of 31-40 years,

- Majority (56.7\%) had General Nursing and Midwifery education, $38.3 \%$ staff nurses had B.Sc Nursing education and 5\% staff nurses had Post Basic B.Sc nursing education.

- Majority (70\%) were having 1-3 years of professional experience, $21.7 \%$ were having $4-6$ years, $6.7 \%$ were having $7-9$ years and $1.7 \%$ were having $>10$ years of experience.

- Majority (40\%) of staff nurses were posted in Medical ward, $28.3 \%$ were posted in Surgical ward and $31.7 \%$ were posted in Obstetrical and Gynaecological wards.

- Majority (86.7\%) attended Inservice education on the topic Nosocomial Infections.

- Majority (38.3.3\%) of staff nurses had attended Inservice Education for more than thrice, 35\% attended once, $23.3 \%$ attended twice and $3.3 \%$ had attended thrice.

2. Findings related to knowledge and selected practices scores of the staff nurses working in various nursing care units regarding the prevention of Nosocomial Infections.

- Majority of (48.3\%) staff nurses were having moderate level of knowledge, $36.67 \%$ staff nurses were having good knowledge score and $15 \%$ staff nurses were having poor knowledge score.

- Majority of (95\%) staff nurses were having average 
hand washing practice score, $3.33 \%$ were having good hand washing practice and $1.67 \%$ were having poor hand washing practice score.

- Majority of (63.33\%) staff nurses were having average IV injection practice score, $36.67 \%$ were having poor IV injection practice score and none of them having good IV injection practice score.

3. Findings related to correlation between knowledge and selected practices scores obtained by staff nurses regarding prevention of Nosocomial Infection.

- There was no significance between knowledge, hand washing practice and IV injection practiceas evident from the ' $r$ ' values of 0.09 and -0.19 respectively less than the table value 0.25 .

4. Findings related to association between knowledge scores and selected practices scores with their demographic variables.

- There was significant association between the knowledge and demographic variables i.e. no. of times attended in service education but there was no significant association between the knowledge and demographic variables i.e. Age, Educational qualification, professional experience, current area of posting, attended in service education on this topic.

- There was significant association between hand washing practice and demographic variable i.e. current area of posting but there was no significant association between hand washing practice and demographic variables i.e. Age in years, educational qualification, professional experience, attended in service education on this topic and no. of times attended in service education on this topic.

- There was significant association between IV injection practice and demographic variables i.e. current area of posting but there was no significant association between IV injection practice and demographic variables i.e. Age in years, Educational qualification, Professional experience, attended in service education on this topic and no. of times attended in service education on this topic.

\section{Discussion}

The present study findings showed that the staff nurses having average knowledge level and average practice scores. These findings were consistent with the findings of the study conducted by Fashafsheh I, Ayed A, Eqtait F, Harazneh L ${ }^{9}$, which revealed that majority of the respondents have fair knowledge level and good practice level regarding infection control. The present study findings were consistent with the study conducted by Kalantarzadeh M, Mohammadnejad E, Ehsani SR, Tamizi $Z^{10}$, to assess the knowledge and practice of nurses about control and prevention of Nosocomial Infections. The study findings showed that the participants had intermediate and high level of knowledge about infection control and had intermediate level of performance. The present study findings revealed that there was no significance between knowledge and selected practices scores. These findings were consistent with the study conducted by Ghadamgahi F, Zighaimat F, Ebadi A, Houshmand $\mathrm{A}^{11}$, that there was not significant relationship between knowledge and self-efficacy. Also, present study revealed that there is significant association between knowledge and demographic variable i.e. no. of times attended in service education and no association with other demographic variables, There is significant association between hand washing and IV injection practice with demographic variable i.e. current area of posting. Similar findings were shown in study conducted by Biberaj P, Gega M, Bimi Indrit ${ }^{12}$, that there was no significant association between course of study and knowledge of students among health care students. Similar study was conducted by Chauhan Krishna, Kumari Kiran ${ }^{13}$, that showed there was not any significant association of level of knowledge with selected demographic variable at 0.05 level of significance.

\section{Conclusion}

The gaps in knowledge and practices regarding prevention of nosocomial infection indicated there is a need to establish a related health care policy. Also study showed that there was no significance between knowledge and practice indicated that there is a need to emphasize staff nurses more about prevention of nosocomial infection and motivate them continuously to practice efficiently, as practicing infection control measures remains a major responsibility of the staff nurses working in a Hospital.

\section{Source of Funding: Self}

Ethical Clearance: Ethical Clearance was taken from Ethical Committee of Holy Family Hospital of New Delhi. 
Conflict of Interest: Nil

\section{References}

1. Basavanthappa B.T. Text book of community health nursing. $2^{\text {nd }}$ ed. New Delhi: Jaypee publication; 2008. p. 18-19.

2. Potter, Perry, Styockert and Hall. Basic nursing. $7^{\text {th }}$ ed. New Delhi: Elsevier publication; 2011. p. 648649

3. Zaryekar R. The trained nurses association of India. Volume 1, Florence Nightingale Lane; Secretary General publication; 2013.

4. Health care without avoidable infections the critical role of infection prevention and control (online). 2016 [cited 2017 Nov 6]; [16 screens]. Available from URL: file://D:/documents/research/ review $\% 20$ of $\% 201$ iterature/WHO-HIS-SDS2016.10-eng(1).pdf

5. Jangwal L, Jangwal KR. Knowledge of infection control measures among nursing students. Nightingale Nursing Times 2016 [cited 2017 Nov 6]; $\operatorname{XII}(5): 32,64$.

6. Laxminarayan R. Hospital-acquired infections high in India: Study. India Medical Times 2011 Sep 22;3 (col.5).

7. Swaminathan S Hospital infection control guidelines [Online]. [2010];[103]. Available from: URL:http://www.cdc.gov/ncidod/dhqp/guidelines. html.

8. Olin J Nursing plays a major role in infection control. [Online]. [2012?] [cited 2012 Mar 5];Available from: URL:http://www.rncentral.com/blog/2012/ nursing-plays-a-major-role-in-infection-control/

9. Fashafsheh I, Ayed A, Eqtait F, Harazneh L. Knowledge and Practice of Nursing Staff towards
Infection Control Measures in the Palestinian Hospitals. JEP [serial online] 2015[cited 2017 Nov 12]; 6(4):82-88. Available from: URL: https:// www.researchgate.net/publication/280805818 Knowledge_and_Practice_of_Nursing_Staff towards_Infection_Control_Measures_in_the Palestinian_Hospitals

10. Kalantarzadeh M, Mohammadnejad E, Ehsani SR, Tamizi Z. Knowledge and Practice of Nurses About the Control and Prevention of Nosocomial Infections in Emergency Departments. Arch Clin Infect Dis [serial online] 2014 [cited 2017 Nov 3]; 9(4):2-3. Available from: URL:https://bmcresnotes. biomedcentral.com/articles/10.1186/s13104-0194533-4

11. Ghadamgahi F, Zighaimat F, Ebadi A, Houshmand A. Knowledge, attitude and self-efficacy of nursing staffs in hospital infections control. IJMR [serial online] 2011 [cited 2017 Nov 4]; 13(3):[6 screens]. Available from: URL:http://www.jehp.net/text. asp?2016/5/1/23/184549

12. Biberaj P, Gega M, Bimi I. Knowledge and Source of Information among Health Care Students on Nosocomial Infections. IJHSSE [serial online] 2014 [cited 2017 Nov 3]; 1(7):48-49. Available from: URL:http://dx.doi.org/10.18203/2320-6012. ijrms20184037

13. Chauhan K, Kumari K. A study to assess the effectiveness of Planned Teaching Program (PTP) on knowledge regarding prevention of Nosocomial Infection among the Staff Nurses working in selected areas of Indira Gandhi Medical College and Hospital, Shimla- Himachal Pradesh. IOSRJNHS [serial online] 2016 [cited 2017 Nov 6]; 5(1):7-8. 